\title{
PENDAMPINGAN PENDIDIKAN KARAKTER MELALUI GUGUSDEPAN
}

\author{
Hidayat $^{1)}$, Dinda Yarshal $^{2)}$, Suratno $^{3)}$ \\ Universitas Muslim Nusantara Al Washliyah
}

\begin{abstract}
ABSTRAK
Menurut Permendikbud no. 63 tahun 2014, pendidikan kepramukaan di sekolah dasar dan menengah merupakan ekstrakurikuler wajib di sekolah. Ekstrakurikuler ini diharapkan menjadi salah satu wadah pembinaan karakter siswa. Namun kompetensi guru pada umumnya sebagai pelaksana kegiatan belum memadai, dimana wawasan dan keterampilan guru tentang kepramukaan masih kurang. SD Negeri No. 067775 Medan sebagai mitra PKM yang sudah memiliki gugusdepan pramuka juga mengalami masalah dalam kompetensi dan wawasan kepramukaan pembinanya. Untuk itu guru sebagai pembina pramuka yang berwenang sebagai pelaksana kegiatan ekstrakurikuler perlu dibekali wawasan dan keterampilan kepramukaan. Tujuan dari program pengabdian ini adalah agar guru terampil melaksanakan pendidikan karakter siswa melalui kegiatan pramuka di sekolah. Untuk mewujudkan tujuan tersebut ada 2 kegiatan yang dilakukan, yaitu briefing singkat dan Traditional Scouting (outdoor activity). Metode yang digunakan adalah pelatihan dalam bentuk teori dan praktek lapangan, Kegiatan teori yang dilakukan dalam penyajian materi dan simulasi. Sedangkan kegiatan praktek lapangan berbentuk role playing dan games. Sehingga guru terampil mendesain dan melaksanakan kegiatan pramuka yang berkualitas di sekolah.
\end{abstract}

Kata kunci: Pendidikan karakter, Gugusdepan, Pendidikan Kepramukaan.

\begin{abstract}
According to Permendikbud no. 63 of 2014, scouting education in primary and secondary schools is compulsory extracurricular in schools. This extracurricular is expected to be one of the ways to develop student character. However, the competence of teachers in general as implementing activities is inadequate, where the insight and skills of teachers about Scouting are still lacking. Public Elementary School No. 067775 Medan as a PKM partner who already has a scout group has also experienced problems in the competency and insight of its scouting coach. For this reason, teachers as scout trainers who are authorized to carry out extracurricular activities need to be equipped with scouting insight and skills. The purpose of this service program is for teachers to be skilled in carrying out student character education through scout activities in schools. To realize this goal there are 2 activities carried out, namely a brief briefing and Traditional Scouting (an outdoor activity). The method used is training in the form of theory and field practice, theoretical activities carried out in the presentation of material and simulations. While the field practice activities take the form of role-playing and games. So that the teacher is skilled at designing and implementing quality scout activities in school.
\end{abstract}

Keywords: Character education, Cluster, Scouting Education.

\section{PENDAHULUAN}

Dalam Kurikulum 2013, pendidikan karakter dilaksanakan secara terintegrasi dalam setiap mata pelajaran. Agar pelaksanaannya dapat lebih terukur, pendidikan karakter diimplementasikan dalam bentuk ekstrakurikuler pendidikan kepramukaan di sekolah. Hal ini didukung melalui Permendikbud No.
63 tahun 2014 yang secara tegas menyatakan bahwa pendidikan kepramukaan sebagai ekstrakurikuler wajib di sekolah dasar dan sekolah menengah [1]. Melalui pendidikan kepramukaan membantu dalam upaya membuat karakter siswa sebagai kaum muda menjadi lebih baik, hal ini secara implisit tertuang dalam UU No. 12 
tahun 2010 [2]. Ini berimplikasi pada kesiapan sekolah dalam melaksanakan ekstrakurikuler tersebut.

Pada kenyataannya di SD Negeri No. 067775 Medan pelaksanaan ekstrakurikuler wajib tersebut belum sebagaimana yang diamanahkan oleh Permendikbud tersebut. Karena keterbatasan kemampuan guru dalam pelaksanaan ekstrakurikuler pendidikan kepramukaan, sekolah mendatangkan pelatih dari luar. Pelatih tersebut tidak mempunyai latar belakang pendidikan guru dan hanya menghandalkan pengalamannya sebagai anggota pramuka, sehingga pelaksanaannya bersifat insidentil, tidak mempunyai silabus dan rencana. Sehingga kegiatan-kegiatan yang dilakukan kurang terintegrasi dalam pengembangan karakter siswa.

Masalah yang mendasar dalam pelaksanaan ekstrakurikuler ini terkait dengan kurangnya kompetensi guru dalam melaksanakan pendidikan karakter. Pendidikan karakter ini berperan dalam pengembangan potensi siswa. Untuk mewujudkan ini diperlukan guru yang kompeten sebagaimana tuntutan Permendiknas No. 16 tahun 2007 yang menyatakan guru harus memiliki kompetensi memfasilitasi pengembangan potensi peserta didik untuk mengaktualisasikan berbagai potensi yang dimiliki [3].

Kebanyakan guru SD Negeri No. 067775 tidak memahami apa itu pramuka, kepramukaan dan gerakan pramuka. Wawasan guru tentang seluk beluk kepramukaan juga menjadi kendala utama. Guru harus memahami pentingnya pembinaan karakter siswa, memahami perkembangan dan kebutuhan peserta didik, menyusun program kegiatan, melaksanakan kegiatan kepramukaan di sekolah. Disamping itu guru dapat mengevaluasi perkembangan peserta didik melalui tanda-tanda penghargaan, tanda pencapaian peserta didik, seperti TKU (Tanda Kecakapan Umum) [4], TKK (Tanda Kecakapan Khusus) [5], dan tanda-tanda lainnya yang menimbulkan motivasi peserta didik.

Salah satu kegiatan baris berbaris siswa SD Negeri 067775 berikut ini menunjukkan bahwa peserta didik tampak belum mahir berbaris, belum berdisiplin dalam berbaris dan kekompakan belum terjalin. Sementara baris berbaris merupakan salah satu alat pendidikan membangun karakter.

Karakter terbentuk dengan pembiasaan-pembiasaan dalam bentuk kegiatan. Kegiatan dalam pramuka meliputi berbagai bidang, seperti pembinaan mental spiritual, rohani, berkerjasama, pendidikan pendahuluan bela negara, cinta tanah air, disiplin dan bersahaja. Nilainilai seperti ini sering luput dari perhatian guru di dalam kelas. Disamping itu ada juga nilai-nilai yang tidak dapat diajarkan di kelas, kalaupun dapat diajarkan terkesan dipaksakan. Sehingga sudah sewajarnya ditumbuhkan nilai-nilai positif tersebut melalui kegiatan pendidikan kepramukaan, sehingga perlu diaktifkan kegiatan ekstrakurikuler pramuka. Hal ini sejalan dengan solusi terhadap nilai karakter yang memprihatinkan, dan dapat membahayakan eksistensi bangsa Indonesia [6] 
Kenyataan yang terjadi, penyelenggaraan pendidikan kepramukaan di sekolah dilakukan sekedar kelihatan ada kegiatan saja, sehingga pembentukan dan pembinaan karakter tidak sepenuhnya dapat berjalan. Hal ini disebabkan ketidakmampuan guru memahami tentang kepramukaan Permasalahan ini juga terjadi pada pramuka yang berpangkalan di SDN No. 067775 Medan. Perhatian yang ditunjukkan oleh sekolah tersebut terhadap pembinaan kepramukaan cukup baik. SDN No. 067775 Medan telah memiliki gugusdepan sebagai pangkalan pembinaan kepramukaan di sekolah. Kendala yang dihadapi sekolah antara lain tidak berjalannya kegiatan kepramukaan secara efektif. Sekolah melibatkan guru-guru sebagai pembina pramuka, namun keterampilan yang dimiliki oleh guru masih kurang. Umumnya guru belum memahami bagaimana sebenarnya pembinaan kepramukaan di sekolah. Dari 24 orang guru yang bertugas, hanya guru olah raga yang telah memiliki pengetahuan tentang kepramukaan. Keterbatasan Pembina pramuka ini menyebabkan pembinaan karakter melalui kegiatan pramuka di sekolah ini belum berjalan dengan baik.

Melihat kondisi yang ada, maka perlu kiranya dilakukan pembinaan dan pendampingan bagi guru-guru SDN No. 067775 Medan tentang pengembangan karakter melalui kepramukaan. Kegiatan pembinaan dan pendampingan ini dilakukan di SDN No. 067775 Medan, mengingat:

1. Guru memiliki minat yang tinggi terhadap pengembangan karakter siswa.
2. Guru memiliki semangat dan tanggungjawab moral terhadap perkembangan karakter siswanya.

Permasalahan utama yang dihadapi mitra dalam pengembangan karakter siswa adalah kurangnya pengetahuan dan kemampuan guru dalam melaksanakan kegiatan ekstrakurikuler kepramukaan. Permasalahan ini dapat diatasi melalui kegiatan Traditional Scouting dan kegiatan Outdoor Acitivy. Kegiatan yang dilakukan merupakan pelatihan dan pembinaan tentang kepramukaan dalam bentuk orientasi, workshop, simulasi, games, praktek lapangan, berkemah dan pendampingan.

Kegiatan Traditional Scouting dimulai dari kegiatan orientasi tentang pendidikan karakter, model karakter, pendidikan kepramukaan, landasan hukum, struktur organisasi gerakan pramuka, dan aktivitas dasar pramuka. Selanjutnya dilakukan workshop penyusunan silabus pendidikan karakter dan pendidikan pramuka, simulasi tentang aktivitas yang memicu karakter. Kegiatan games dilakukan untuk aktivitas-aktivitas khusus sesama guru. Selanjutnya dilakukan Outdoor activity yang terdiri dari kegiatan berkemah dan praktek lapangan. Juga dilakukan pendampingan cara berlatih melakukan pembinaan karakter terhadap peserta didik gugusdepan.

\section{METODE PELAKSANAAN}

Program Kemitraan Masyarakat ini terdiri dari 2 kegiatan, yakni Traditional Scouting dan Outdoor Activity. Pada kegiatan Traditional Scouting dilaksanakan 
melalui 5 (lima) metode, yaitu orientasi, workshop, simulasi, games, dan pendampingan. Sedangkan kegiatan Outdoor Activity dilaksanakan melalui 3 (tiga) metode yaitu: praktek lapangan, berkemah, dan pendampingan. Alur pelaksanaan kegiatan digambarkan pada bagan berikut:

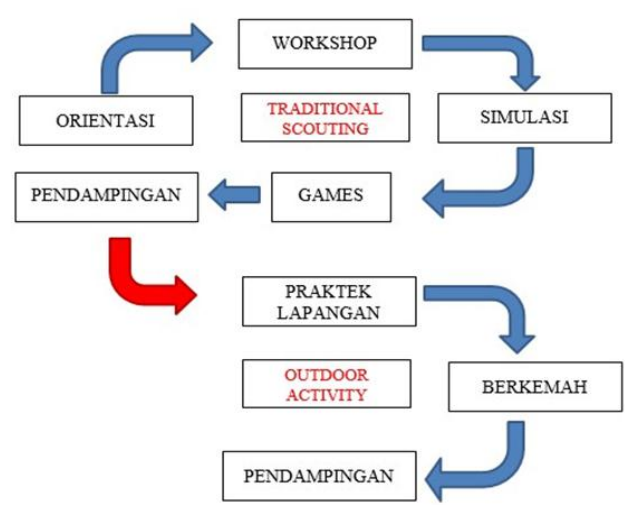

Gambar 1. Alur pelaksanaan kegiatan

Deskripsi kegiatan yang dilakukan diuraikan pada tabel berikut:

Tabel 1. Tabel Uraian Kegiatan

\begin{tabular}{|c|c|c|}
\hline Kegiatan & Metode Pelaksanaan & Uraian Kegiatan \\
\hline \multirow[t]{5}{*}{$\begin{array}{l}\text { Traditional } \\
\text { Scouting }\end{array}$} & Orientasi & $\begin{array}{ll}\text { - } & \text { Penyajian materi pendidikan karakter } \\
\text { - } & \text { Penyajian materi pendidikan pramuka berbasis } \\
& \text { gugusdepan }\end{array}$ \\
\hline & Workshop & $\begin{array}{l}\text { - Pembimbingan dalam menyusun silabus pendidikan } \\
\text { karakter } \\
\text { - Pembimbingan dalam menyusun silabus pendidikan } \\
\text { pramuka berbasis gugsdepan } \\
\text { - Pembimbingan dalam menyusun modul praktek lapangan }\end{array}$ \\
\hline & Simulasi & $\begin{array}{l}\text { - Peserta mempresentasikan silabus pembinaan karakter } \\
\text { yang mereka kembangkan } \\
\text { - Peserta mempresentasikan pola pembinaan pendidikan } \\
\text { kepramukaan berbasis gugusdepan }\end{array}$ \\
\hline & Games & $\begin{array}{l}\text { - Peserta dibimbing dalam permainan pembinaan karakter } \\
\text { - } \\
\text { Peserta dibimbing dalam permainan tantangan kecakapan } \\
\text { - } \\
\text { Peserta menggunakan model Two Stay Two Stray dalam } \\
\text { menerapkan pendidikan kepramukaan }\end{array}$ \\
\hline & Pendampingan & $\begin{array}{l}\text { - Pembimbingan dalam pembinaan karakter siswa di } \\
\text { sekolah } \\
\text { - } \quad \begin{array}{l}\text { Pembimbingan dalam pembinaan pramuka pada } \\
\text { gugusdepan sekolah }\end{array}\end{array}$ \\
\hline \multirow[t]{3}{*}{$\begin{array}{l}\text { Outdoor } \\
\text { Activity }\end{array}$} & Praktek Lapangan & $\begin{array}{l}\text { - Peserta melakukan praktek pembinaan karakter bagi } \\
\text { siswanya } \\
\text { - Peserta melakukan praktek pola pembinaan pramuka bagi } \\
\text { siswa }\end{array}$ \\
\hline & Berkemah & $\begin{array}{l}\text { - Peserta dibimbing dalam pelaksanaan kegiatan berkemah } \\
\text { - Peserta dibimbing untuk dapat hidup di alam terbuka }\end{array}$ \\
\hline & Pendampingan & $\begin{array}{l}\text { - Pembimbingan dalam menyusun kegiatan perkemahan } \\
\text { - Pembimbingan dalam menyusun outdoor activity yang } \\
\text { dilakukan siswa di perkemahan }\end{array}$ \\
\hline
\end{tabular}




\section{HASIL DAN PEMBAHASAN}

Pada awal kegiatan pengabdian diadakan pretes untuk mengetahui pengetahuan awak guru tentang kepramukaan. Terdapat 8 (delapan) orang guru yang mengikuti pretes 2 (dua) orang mendapat nilai 40, 3 (tiga) orang mendapat nilai 45 , satu orang mendapat nilai 50 dan 2 (dua) orang mendapat nilai 55. Tampak bahwa guru memiliki pengetahuan yang minim tentang kepramukaan.

Tahapan selanjutnya pelaksana melakukan kegiatan orientasi kepada guru-guru dengan materi pendidikan karakter dan materi kepramukaan. Pada kegiatan orientasi dimulai dengan menjelaskan Permendikbud No. 63 tahun 2014 tentang Pendidikan Kepramukaan sebagai Kegiatan Ekstrakurikuler Wajib Pada Pendidikan Dasar Dan Pendidikan Menengah. Penyajian materi ini dimaksudkan agar guru memiliki pemahaman tentang kegiatan ekstrakurikuler wajib pendidikan kepramukaan di sekolah.

\section{Kegiatan selanjutnya, penjelasan tentang pendidikan kepramukaan melalui gugusdepan di sekolah. Kegiatannya berupa teori dan praktek.}

Materi teori terdiri dari: Prinsip dasar dan metode kepramukaan, motto gerakan pramuka, kiasan dasar, struktur organisasi gugusdepan, dan majelis pembimbing, serta materi teknik kepramukaan. Materi teknik kepramukaan terdiri dari: baris berbaris, formasi barisan, sandi, morse, semaphore, tanda jejak, keterampilan berkemah, dan penanaman nilai patriotisme.

Selain kegiatan di atas, teoritis dibarengi dengan praktek lapangan dengan materi: baris berbaris, formasi barisan, sandi, morse, semaphore, tanda jejak, keterampilan berkemah, dan penanaman nilai patriotisme.

Kegiatan praktek yang penting dikuasai oleh pembina dan peserta didik antara lain: baris berbaris, formasi barisan. Ini diperlukan agar mereka dapat melaksanakan upacara pembukaan latihan dan penutupan latihan, dengan formasi lingkaran untuk golongan siaga dan formasi angkare untuk golongan penggalang. Berikut ini beberapa gambar kegiatan lapangan;

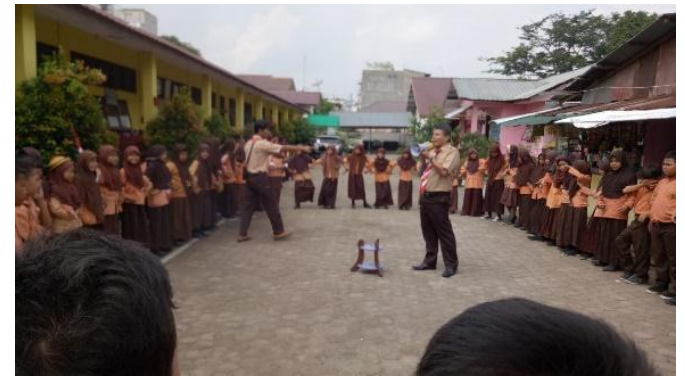

Gambar 2. Upacara Pembukaan Latihan Golongan Siaga

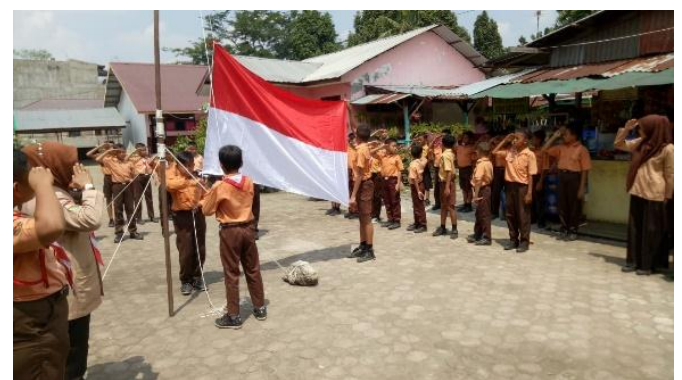

Gambar 3. Upacara Pembukaan Latihan Penggalang.

Teknik kepramukaan yang latihkan kepada peserta/ guru berupa : tali temali. Ada 6 jenis simpul yang utama, yakni: simpul mati, simpul anyam, simpul anyam berganda, simpul pangkal, simpul jangkar, simpul kembar. 


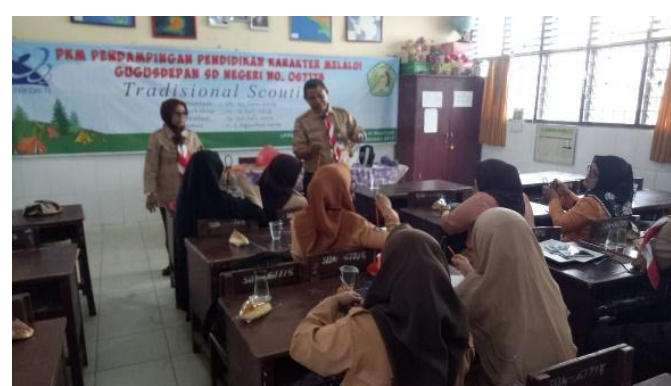

Gambar 4. Latihan Tali temali.

\section{KESIMPULAN}

Simpulan pelaksanaan kegiatan pengabdian bahwa aktivitas traditional scouting memberikan pengalaman dan pengetahuan baru bagi guru-guru dan diharapkan dapat dikembangkan oleh guru dalam pengembangan pendidikan karakter melalui gugusdepan di sekolah.

Diharapkan kepada sekolah dapat membangun komunikasi kepada pelaksana pengabdian agar dapat dilakukan pendampingan kegiatan, agar pembinaan karakter dapat berlangsung secara berkesinambungan.

\section{REFERENSI}

Hanafi. "Pendidikan Karakter dalan Gerakan Pramuka". Jurnal Pendidikan Karakter Jawara Volume 1 No. 1 tahun 2015. ISSN 2442-7780

Keputusan Kwartir Nasional Gerakan Pramuka Nomor: 058 Tahun 1982 Tentang Petunjuk Penyelenggaraan Tanda Kecakapan Umum

Keputusan Kwartir Nasional Gerakan Pramuka Nomor: 134/KN/76 Tahun 1976 Tentang petunjuk
Penyelenggaraan Kecakapan Khusus

Tanda

Permendikbud Nomor 63 tahun 2014 tentang Pendidikan Kepramukaan Sebagai Kegiatan Ekstrakurikuler Wajib Pada Pendidikan Dasar Dan Pendidikan Menengah

Permendiknas No. 16 tahun 2007 tentang Standar Kualifikasi Akademik dan Kompetensi

Undang-undang no. 12 Tahun 2010 tentang Gerakan Pramuka. 